\title{
我国能源生产、消费、储能现状及碳中和条件下变化 趋势
}

张永生 ${ }^{*}$, 董舵, 肖逸, 汪涛, 王家伟

华北电力大学能源动力与机械工程学院, 电站能量传递转化与系统教育部重点实验室, 北京 102206

* 联系人, E-mail: yszhang@ncepu.edu.cn

2021-08-07 收稿, 2021-09-27 修回, 2021-09-28 接受, 2021-10-08 网络版发表

摘要 碳达峰、碳中和是我国能源发展的重大需求和挑战. 本文以实现碳中和为目标, 基于统计数据分析了我国 现有能源生产结构、电力装机、不同行业能源及电力消费等特点, 进而讨论实现碳中和目标下的能源结构和我国 未来电力系统结构调整面临的问题及瓶颈. 主要结论包括: 实现碳中和目标, 风、光可再生装机将是现有火电装机 的 2 倍左右, 需要调整现有的能源生产和消费模式, 并配置适当的储能容量; 现有技术水平下, 抽水蓄能、电化学储 能、氢能具有竞争力, 但抽水蓄能受限于地理环境, 锂离子电池受限于锂资源, 氢能燃料电池受限于铂资源, 都有 发展瓶颈; 消纳可再生能源需要考虑多种储能技术储备, 氢燃气轮机、氢冶炼等相对成熟的路线技术具有支撑今 后大规模可再生能源消纳的潜在优势. 分布式储热、压缩空气储能、非贵金属催化的氢燃料电池、钠/铅酸电池、 液流电池、超级电容器及其他多种具有技术经济性、可实现大规模应用的储能技术也都具有良好的发展空间.

关键词碳中和, 能源生产消费, 风电, 太阳能发电, 储能, 氢能

目前，我国处于从化石能源为主体向新能源为主 体转型的历史过渡阶段, 力争实现“2030年碳达峰、 2060年碳中和”目标. 总体来说，在任何一个历史时期， 现有生产、消费模式是当前条件下技术与经济的最佳 匹配, 具有存在的合理性. 分析现有能源生产、消费结 构，并在此基础上探讨2060年碳中和的实现途径及相 关问题, 对我国能源发展具有重要意义.

2019年, 我国国内生产总值达到 99.1 万亿元 ${ }^{[1]}$, 占 世界经济比重超过 $16 \%$. 能源支撑了我国经济的发展. 2018年，我国能源生产占世界的比例为 $17.8 \%$, 能源消 费占世界的比例为 $20.8 \%{ }^{[2]}$. 传统上, 我国能源生产和消 费以化石能源为主. 然而, 从资源角度考虑, 我国化石 能源探明储量并不丰富. 截至2020年底, 我国煤炭占世 界的比例为 $13.3 \%$, 石油占世界的比例为 $1.5 \%$, 天然气 占世界的比例为 $4.5 \%{ }^{[3]}$, 对可靠支撑经济社会的永续
发展具有潜在风险, 同时排放大量二氧化碳.

可再生新能源资源不会枯竭, 若不开发, 则会导致 可用能量流失. 我国陆地 $70 \mathrm{~m}$ 高度风能资源技术可开 发量有 72 亿 $\mathrm{kW}$ (中国气象局风能太阳能资源中心, 全 国风能资源评估成果，2014年)，至少有 7 亿 $\mathrm{kW}$ 的海上 风电具有开发潜力 ${ }^{[4]}$. 太阳能方面, 仅处于青藏高原、 甘肃、新疆、内蒙古等极度丰富区和丰富区的太阳能 资源就有约 4 千万亿 $\mathrm{kW} \mathrm{h}$ 的年总辐射能量 ${ }^{[5]}$. 水电可开 发装机容量为 5.4 亿 $\mathrm{kW}^{[6]}$. 目前, 我国风电、光伏、水 电装机规模均居世界第一, 同时, 我国是世界唯一拥有 联合国产业分类中全部工业门类的国家，是制造业世 界第一大国, 新能源发展所需的产能优势明显, 具有良 好的能源转型基础.

能源消费最终体现在第一产业、第二产业、第三 产业的生产活动和生活消费中. 农业现代化中机械化

引用格式: 张永生, 董舵, 肖逸, 等. 我国能源生产、消费、储能现状及碳中和条件下变化趋势. 科学通报, 2021, 66: 4466-4476

Zhang Y S, Dong D, Xiao Y, et al. Current status and trends in energy production, consumption, and storage under carbon neutrality conditions in China (in Chinese). Chin Sci Bull, 2021, 66: 4466-4476, doi: 10.1360/TB-2021-0797 
取代役畜、使用更多的合成含氮化合物和增加防护性 农药都会增加能量的消耗. 我国制造业增加值占全球 的比重为 $25 \%$ 左右，作为未完全实现工业化的发展中 国家，我国要避免“脱实向虚”[7]，对能源的需求不会显 著下降. 现有发达国家第三产业比重普遍较高, 我国发 展过程中如果增加其比重，对能源也有潜在的巨大 需求.

如果处理不好能源生产、消费，将会严重制约国 家的良性发展，我国以碳中和为抓手开展能源结构调 整恰逢其时. 本文基于我国官方统计数据(如无说明,

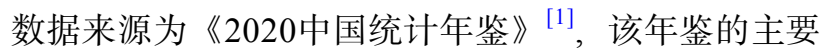
数据统计到2019年，部分数据统计到2018年), 分析我 国实现碳中和目标的重点和途径.

\section{1 中国能源结构预测}

目前我国能源结构以化石能源为主体，2019年化 石能源占能源消费总量的比重为 $84.7 \%$. 调整能源结构 是实现碳达峰、碳中和目标的主要途径. 未来我国的 能源结构将逐渐转变为以太阳能、风能、水能等可再 生能源及核能为主. 国际能源署(International Energy Agency, IEA $)^{[8]}$ 、英国石油公司(British Petroleum, BP $)^{[9] 、}$ 中国石油经济技术研究院(CNPC Economics and Technology Research Institute, ETRI) ${ }^{[10]}{ }^{\text {等机构考虑不同情景 }}$ 对我国能源结构进行了预测. 基于这些机构的分析结 果和对我国经济社会发展的预测，给出了一个基本判 断和假设(单位折算到标准煤汇总于表1): 到2060年, 我国能源消费总量不会有大的变化; 要实现碳中和, 化 石燃料比例在 $20 \%$ 左右, 可再生能源比例在 $70 \%$ 左右.

\section{2 目前能源生产和消费分析}

\section{1 能源生产}

从图1(a)可见，随着我国经济的快速发展，一次能 源生产基本上一直处于上升趋势，生产总量由1990年 的10.4亿吨标准煤增长到2019年的39.7亿吨标准煤，增 长了 2.8 倍, 且2000年后增加尤其明显. 图1(b)数据表明, 煤炭、石油、天然气等化石能源在能源生产中的占比 高，2019年化石能源总占比为 $81.2 \%$ ，且以煤炭为主. 2011年，煤炭生产占比达到最大值 $77.8 \%$ ，随后缓慢降 低，但2019年煤炭生产量依然高达 $68.6 \%$ 。基于不同能 源形式的特征，能源转型最终要实现化石燃料利用为 主向可再生电力为主的转型.

电力是能源的重要转化形式, 电力装机容量与经 济发展正相关. 从图2(a)可见，我国发电装机容量增长 趋势明显, 2000年后增加尤为显著: 1990 2000年, 从1.4 亿kW增长到3.2亿kW, 10年增长到2.3倍; 2000 2019年, 进一步增长到20.1亿kW，9年增长到6.3倍. 由图2(b)可 知，目前我国电力装机主要由火电、水电、风电、太 阳能发电和核电构成，火电是主体，一直在 $50 \%$ 以上. 水电装机基本比较平稳，在 $20 \%$ 左右. 可再生能源装机 容量比例初期较小但发展迅速，由 2008 年的 $2 \%$ 增长到 2019年的 $23 \%$. 从发电量来看，风光发电量由 2010 年的 0.06 万亿 $\mathrm{kW}$ h增长到 2018 年的 0.53 万亿 $\mathrm{kW} \mathrm{h}$ ，增加了 7.8 倍(图2(c)). 不同于燃煤发电，风光年利用小时数较 低. 因此, 尽管我国的风电装机、光伏发电装机规模都 处于世界第一的水平, 但总发电量占比仍然很低. 2018 年, 风光可再生能源发电量占比只有 7.4\%(图2(d)).

表 1 中国能源发展预测(单位: 亿吨标准煤)

Table 1 Estimation energy development of China (Unit: 100 million tons of standard coal) ${ }^{[8-10]}$

\begin{tabular}{|c|c|c|c|c|c|c|c|c|c|}
\hline \multirow{2}{*}{ 机构 } & \multicolumn{3}{|c|}{ 2030年 } & \multicolumn{3}{|c|}{ 2040年 } & \multicolumn{3}{|c|}{ 2050年 } \\
\hline & 化石燃料 & 核能 & 可再生 & 化石燃料 & 核能 & 可再生 & 化石燃料 & 核能 & 可再生 \\
\hline IEA-SPS & 44 & 2 & 7 & 43 & 4 & 10 & I & I & I \\
\hline IEA-CPS & 47 & 2 & 7 & 48 & 4 & 9 & I & I & I \\
\hline IEA-SDS & 35 & 3 & 9 & 23 & 5 & 14 & I & I & I \\
\hline BP-BAU & 40 & 2 & 12 & 36 & 4 & 15 & 31 & 5 & 17 \\
\hline BP-RT & 36 & 2 & 15 & 24 & 4 & 24 & 13 & 5 & 29 \\
\hline BP-NZ & 34 & 2 & 17 & 17 & 4 & 30 & 10 & 6 & 32 \\
\hline ETRI-BAU & 41 & 1 & 13 & 40 & 3 & 14 & 35 & 4 & 17 \\
\hline
\end{tabular}

a) SPS: Special policy scenario, 既定政策情景; CPS: Current policy scenario, 当前政策情景; SDS: Sustainable development scenario, 可持续发 展情景; BAU: Baseline scenario, 基准情景; RT: Rapid transformation scenario, 快速转型情景; NZ: Net zero scenario, 净零情景; “”表示无数值 

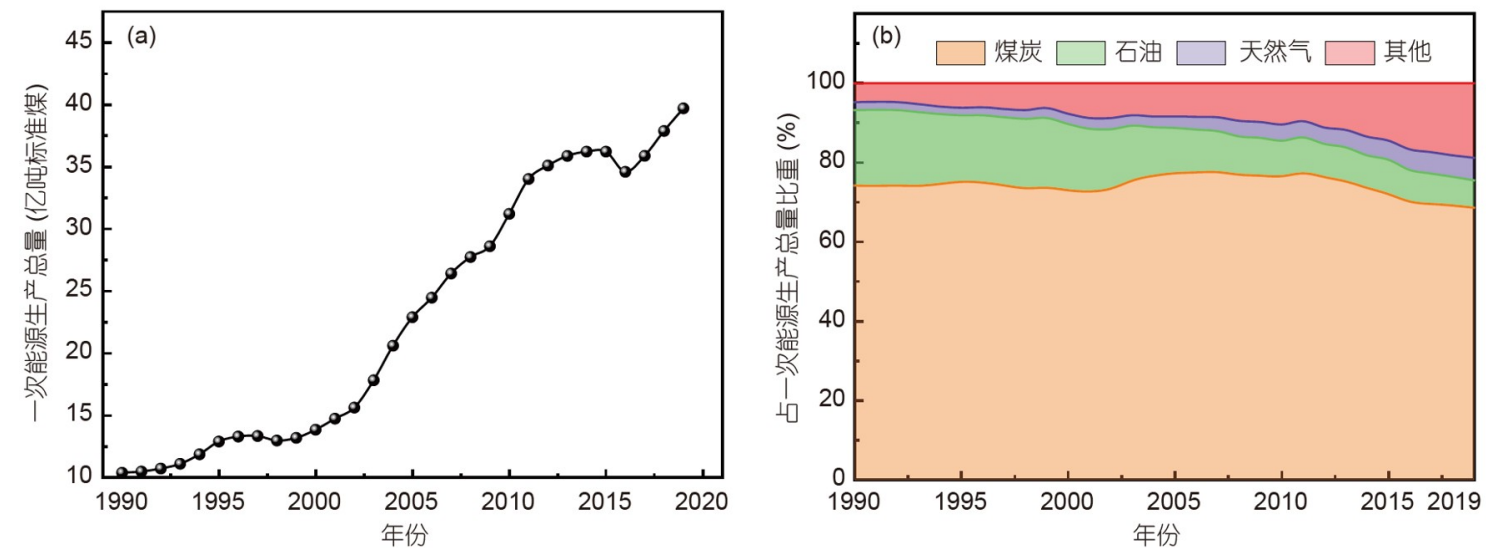

图 1 中国一次能源生产. (a) 能源生产总量; (b) 一次能源结构

Figure 1 Primary energy production of China. (a) Total primary energy production; (b) composition of the primary energy structure
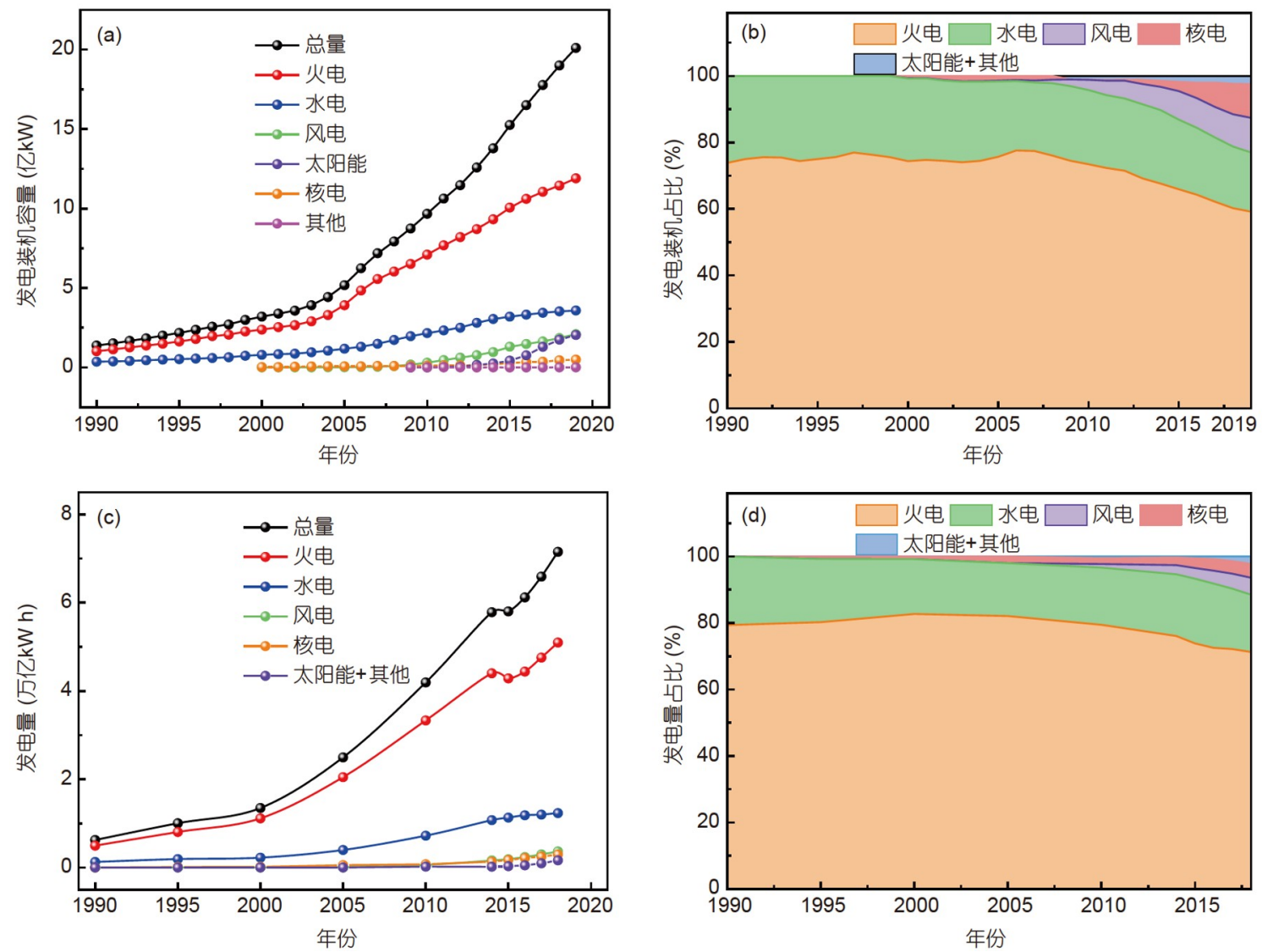

图 2 中国电力装机及发电量. (a) 发电装机容量; (b) 发电装机占比; (c) 发电量; (d) 发电量占比

Figure 2 Installed electric power capacity and electric power generation in China. (a) Installed electric power capacity; (b) proportion of the installed electric power capacity; (c) electric power generation; (d) proportion of the electric power generation

\section{2 能源消费}

图3给出了我国能源消费的发展情况. 图3(a)显示, 1990 年能源消费总量为 9.9 亿吨标准煤. 21 世纪以来,
消费总量快速增长, 从2000年的 14.7 亿吨标准煤增长 到2019年的 48.7 亿吨标准煤, 增长了 2.3 倍. 同时, 前 15 年煤炭消费的增加趋势与能源消费的增长趋势基本保 
持一致. 2015年以来，我国煤炭消费量趋于平缓，消费 量在 27 亿吨标准煤左右. 煤炭消费占比基本处于不断 下降的趋势，由 2007 年的峰值 $72.5 \%$ 连续降至 2019 年的 57.7\%(图3(b)).

将煤炭、焦炭、原油、汽油、煤油、柴油、燃料 油、天然气、电力统计在内, 按行业能源消费的情况 如图4(a)所示(统计年鉴最新数据为2018年). 我国能源 总消费量主要由工业消费、居民消费和交通消费(运 输、仓储、邮政)组成, 其余消费占比较小. 可见, 工业 消费量与能源总消费量变化趋势一致，且工业消费占 能源总消费比例保持在 $65 \%$ 75\% 之间(图4(b)), 支撑了 我国巨大的工业产能和国民经济建设. 此外, 居民生活 和交通能源消费也在不断增加.

\subsection{1 电力消费}

今后我国构建以新能源为主体的新型电力系统,

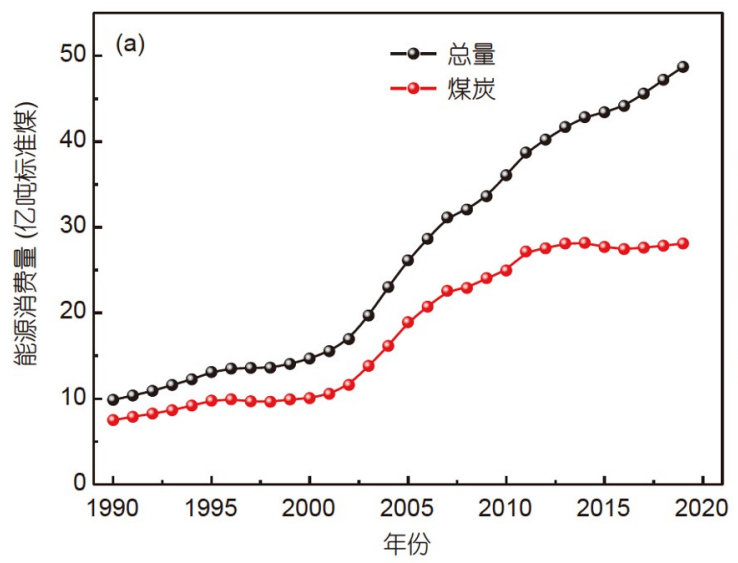

电力消费在能源消费中的比例将会进一步加大. 本文 将目前能源消费折算为电力, 不同行业的电力消耗情 况如图5(a)所示，基本趋势与图4(a)一致. 若2019年能 源消费总量全部由电力提供, 全年需要 39.6 万亿 $\mathrm{kW} \mathrm{h}$.

图5(b)是不同行业的实际电力消费，要达到图5(a) 的结果, 大多数行业的电力需求要增加 $4 \sim 5$ 倍, 缺口巨 大. 从图5(b)居民生活和交通电耗可见，两方面的能源 消费量都在不断增加. 2018年, 居民生活及交通消费占 能源总消费量比重分别为 $15.4 \%$ 和 $9.7 \%$, 未来也存在增 长的趋势.

图5(c)是对比了图2(c)和5(b)的结果, 发现目前工 业用电量与火力发电量惊人地一致. 从发电侧和用电 侧来看, 火力发电调峰调频相对方便, 工业生产流程工 艺可以优化, 人为调控的空间都很大, 两者进行优化匹 配对于今后我国电力结构调整具有重大意义.

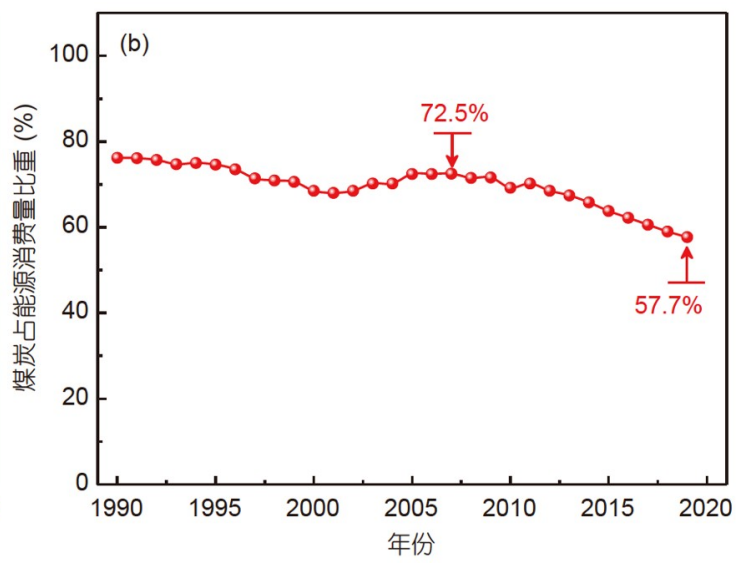

图 3 中国能源消费. (a) 煤炭及能源消费量; (b) 煤炭占能源消费量比重

Figure 3 Energy consumption in China. (a) Coal and energy consumption; (b) proportion of coal in total energy consumption
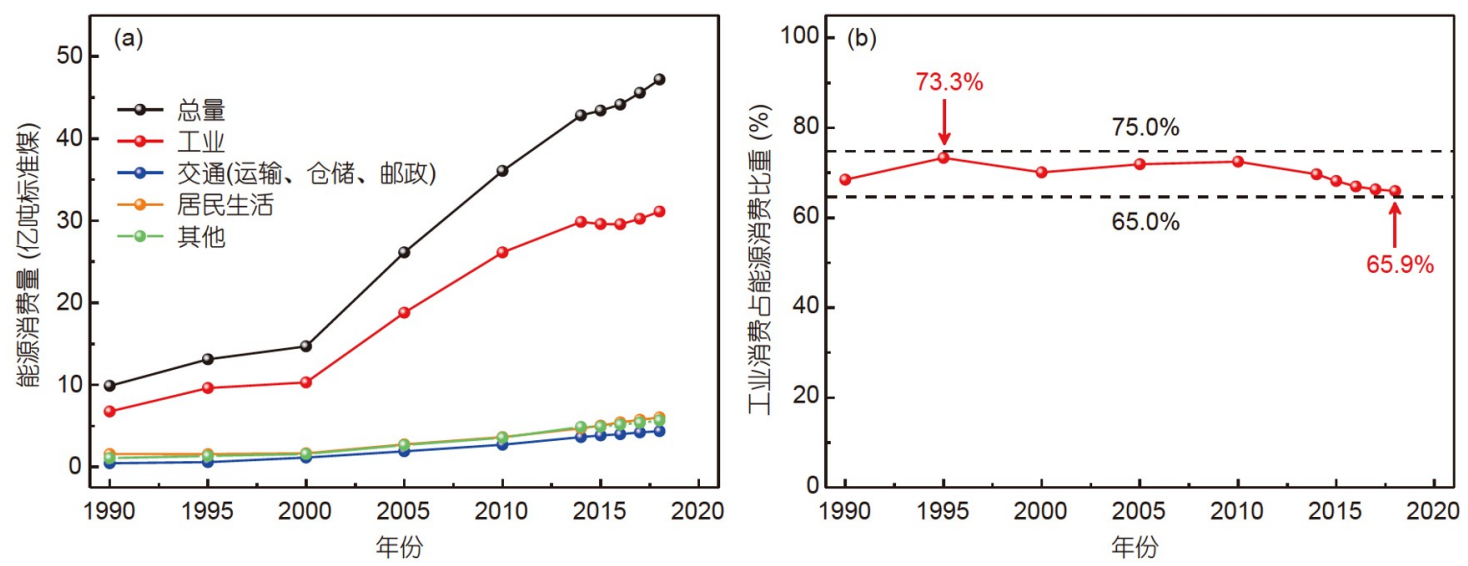

图 4 按行业能源消费. (a) 不同行业能源消费趋势; (b) 工业消费占能源消费比重

Figure 4 Energy consumption by sectors. (a) Energy consumption trends by sectors; (b) proportion of industry in total energy consumption 

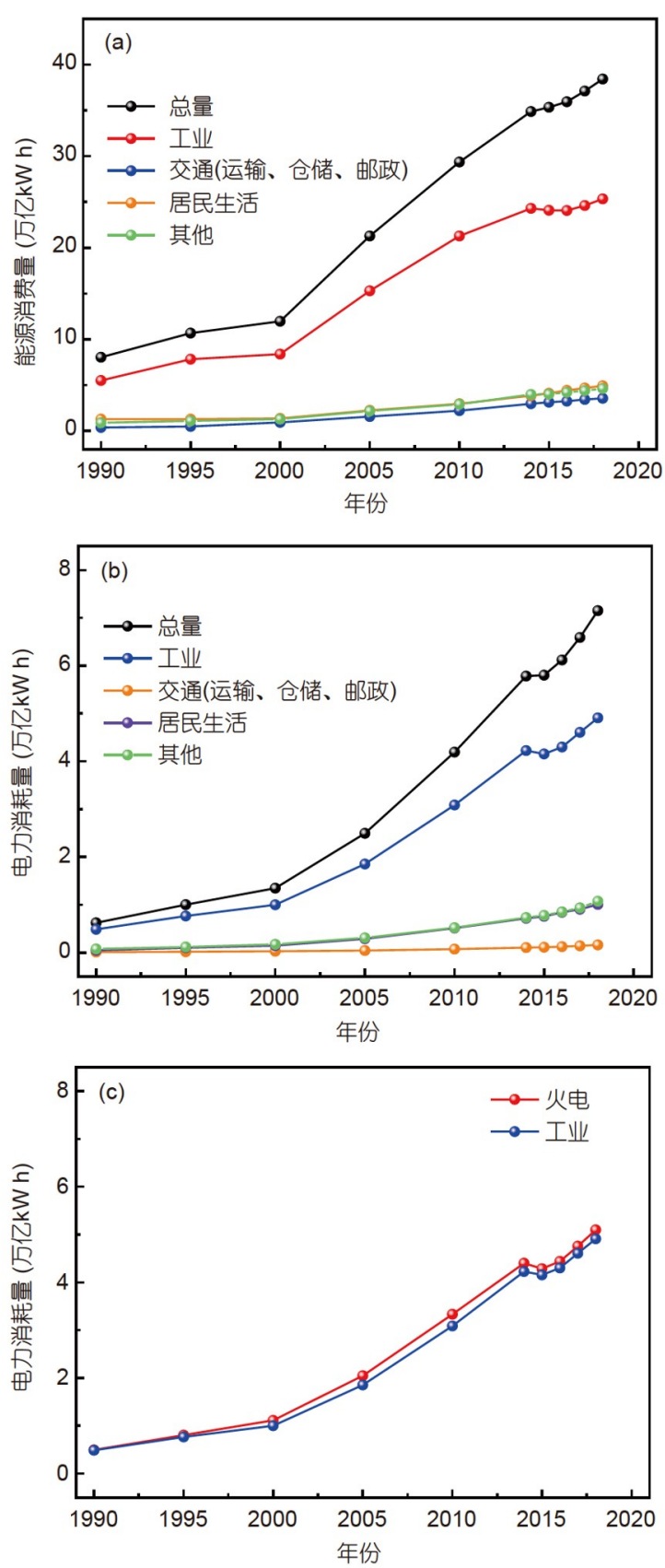

图 5 按行业电力消耗. (a) 不同行业能源消费折算电力消耗; (b) 不 同行业电力消耗量; (c) 火电与工业电耗比较

Figure 5 Electric consumption by sectors. (a) Conversion of energy consumption into electric consumption by sectors; (b) electric consumption by sectors; (c) comparison of fossil fuel fired electric generation and industrial electric consumption

\subsection{2 工业及交通石油消费}

我国石油对外依存度高, 2019 年依存度达到 $71 \%{ }^{[11]}$. 从图6我国石油消费变化中可见，其主要用于 工业和交通领域. 尽管工业领域石油消费占比逐渐缩 小，从1990年的63.8\%降至2018年的36.1\%(图6(b))，但 消费总量仍处于上升趋势. 交通领域石油消费量不断 增加，消费占比也在不断增长，从1900年的 $14.7 \%$ 增长 到2018年的 $36.5 \%$ (图6(b)), 是目前最大的石油消费 领域.

今后交通能源消费中, 电动汽车占比会逐渐加大. 本文考虑电动汽车替代目前的燃油车以计算交通能耗 对应的电力消费. 其中, 交通耗油折算电力以比亚迪、 小鹏、特斯拉电动汽车为例, 比亚迪汉的百公里电耗 量为 $12.7 \mathrm{~kW} \mathrm{~h}$ ，小鹏P7的为 $12.1 \mathrm{~kW} \mathrm{~h}$, 特斯拉Model3 的为 $12.7 \mathrm{~kW} \mathrm{~h}$, 取平均百公里电耗量为 $12.5 \mathrm{~kW} \mathrm{~h}$ (中国 工业和信息化部政务服务平台中国汽车能源消耗量查 询: https://yhgscx.miit.gov.cn/fuel-consumption-web/ mainPage; 汽车之家: https://www.autohome.com.cn/beijing/). 选取宝马 3 系、奥迪 $\mathrm{A} 4 \mathrm{~L}$ 、奔驰 $C$ 级和大众帕萨 特 4 款汽油车为例, 平均百公里油耗为 $6.33 \mathrm{~L}$, 汽油密度 为 $0.74 \mathrm{~g} / \mathrm{cm}^{3}$, 根据式(1)和国家统计局 2018 年炼油数据 及资源消费量计算, $1 \mathrm{~kg}$ 石油可折算为 $2.67 \mathrm{~kW} \mathrm{~h}$ :

$\alpha_{\text {石油, 电量 }}=\frac{Q_{\text {百公里 }}}{v_{\text {百公里 }} \rho}$,

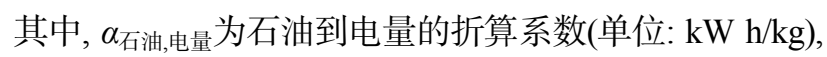

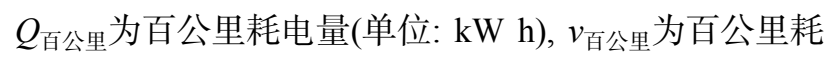
油量(单位: L), $\rho$ 为汽油密度(单位: $\mathrm{g} / \mathrm{cm}^{3}$ ).

计算可得，2018年交通消耗石油折算成电力消耗, 数值为 0.61 万亿 $\mathrm{kW} \mathrm{h}$, 如图6(b)所示. 与当年电力消耗 对比，2018年交通耗油折算电耗占电力消耗的 $8.49 \%$, 且增长趋势明显. 工业耗油折算电耗占总电力耗能的 $8.39 \%$.

\section{3 能源结构调整瓶颈和解决途径分析}

能源结构向新能源为主体转型、构建以新能源为 主体的新型电力系统, 核心在于风电、太阳能发电的 大规模应用. 我国具有世界领先的工业产能优势, 风 电、光伏发电技术成熟, 能够逐渐实现平价上网, 使风 电、太阳能发电具备了承担发电主体责任的基础.

然而，空间分布的不均匀性和时间分布上的间歇 性、随机性和波动性导致风电、太阳能发电上网匹配 用户困难极大. 要实现能源的安全稳定供应, 第一, 需 要有比现有电力总装机更大规模的装机容量; 第二, 需 要考虑全社会的能源供应与需求, 调整生产和消费模 式; 第三, 需要配置适当的储能容量平抑供需平衡. 


\section{1 装机容量预测}

2019年, 我国一次能源消费中, 煤炭、石油、天然 气占比为 $84.7 \%$. 电力总装机为 20.1 亿 $\mathrm{kW}$, 风电、太阳 能发电装机为 4.1 亿 $\mathrm{kW}$ (占全部发电总装机的 $20.61 \%$ ), 详见表2.

对今后能源消费及结构绝对准确的预测是困难的, 本文基于目前的相关信息给出初步判断，方便读者有 一个宏观量级上的概念. 能源消费需求以2019年发电 量为基准，假设实现碳中和，电量分别由火电供应 $20 \%$ 、水电供应 $20 \%$ 、风电供应 $25 \%$ 、太阳能供应 $25 \%$ 、核电供应 $10 \%$, 各种发电形式的年利用小时按照 2019年水平考虑. 预测装机容量如表2所示，得出两个 主要结论: (1) 总发电装机容量是目前的1.6倍; (2) 风 电、太阳能发电装机容量为 23.85 亿 $\mathrm{kW}$, 是目前装机的 5.8 倍, 是目前火电装机的 2 倍, 对应发电量为 35710 亿

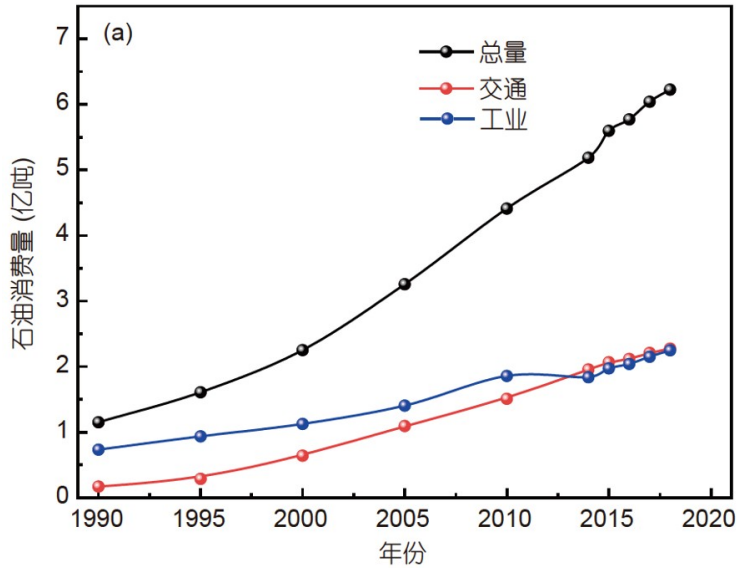

$\mathrm{kW}$ h. 尽管如此，以电力消费预测能源消费显然是保 守的，而且今后风、光发电资源条件比现有存量装机 的资源条件可能会更差. 因此, 风电、太阳能发电装机 在上述预测的基础上进一步增加的可能性很大.

\section{2 能源生产与消费模式}

碳中和目标下，能源生产由化石能源为主向风 电、太阳能发电、水电、核电等新能源为主逐渐转变.

从按行业分能源消费量来看, 2018年我国47.2亿吨 标准煤消费中，工业消费占比为 $65.9 \%$. 工业包括采矿 业、制造业、电力/热力/燃气及水产业和供应业. 将这 些行业进一步细分，其中煤炭开采和洗选业、石油和 天然气开采业、石油/煤炭及其他燃料加工业、化学原 料和化学制品制造业、非金属矿物制造业、黑色金属 冶炼和压延加工业、有色金属冶炼和压延加工业、电

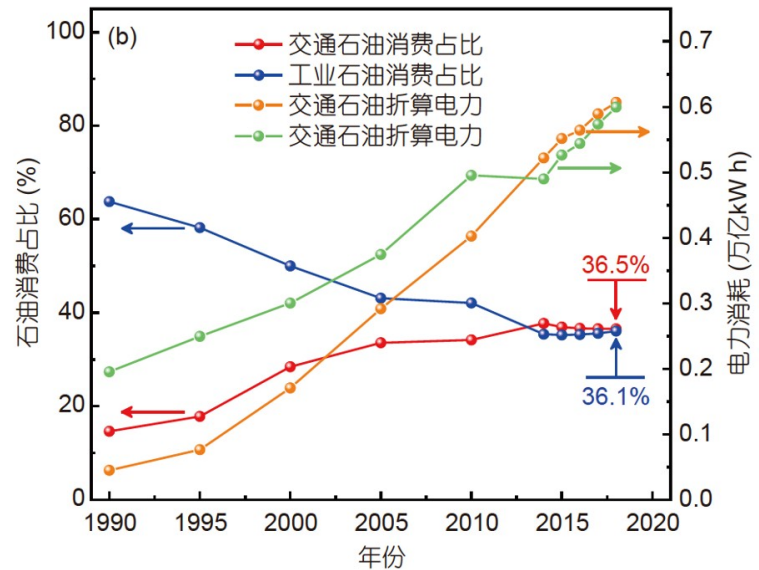

图 6 工业及交通石油消费. (a) 石油消耗量; (b) 工业、交通石油消耗占比及折算

Figure 6 Petroleum consumed in industry and transport sectors. (a) Petroleum consumption; (b) proportion and conversion of petroleum consumed in industry and transport sectors

表 2 中国2019年发电装机及碳中和装机预测 ${ }^{\mathrm{a}}$

Table 2 Installed electric capacity in 2019 and estimation under carbon neutralization scenario of China

\begin{tabular}{ccccc}
\hline 发电形式 & 装机容量(亿kW) & 发电量(亿kW h) & 年利用小时 $(\mathrm{h})$ & 碳中和装机容量(亿kW) \\
\hline 火电 & 11.89 & 51653 & 4293 & 3.33 \\
水电 & 3.58 & 11534 & 3726 & 3.83 \\
核电 & 0.49 & 3484 & 7394 & 0.97 \\
风电 & 2.09 & 3577 & 2082 & 8.58 \\
太阳能 & 2.04 & 1172 & 1169 & 15.27 \\
其他 & 0.0037 & $/$ & $/$ & $/$ \\
\hline
\end{tabular}

a) 年利用小时除太阳能为国家能源局统计数据, 其他为中国电力企业联合会统计数据; 国家能源局统计年利用小时为全国 $6000 \mathrm{kW及以}$ 上电厂发电设备对应的时间; “”表示无数值 
力/热力生产和供应业、燃气生产和供应业等, 是消费 煤炭、焦炭、原油、天然气等化石能源的主要行业, 化石能源作为燃料或原料用于这些行业的相关工艺业 过程. 上述行业合计能源消费占工业能源消费量的 $78.9 \%$, 占总能源消费的 $52.0 \%$.

碳中和不是不使用化石能源, 需要在全社会成本 最低的前提下考虑什么领域的化石能源不可替代, 或 者代价最大. 碳中和能源转型中, 化石能源“热”利用替 代方案比较清晰, 通过可再生能源发电转化可以代替 其提供动能、热能、电能. 化石能源“化学”利用替代 尚不明确, 比如, 我国2019年消费了4.4亿吨焦炭, 主要 用于作为冶金还原剂, 目前还缺乏完全成熟的技术体 系替代. 因此, 相关化石能源生产行业会面临缩减, 以 化石燃料为原料的行业需要考虑原料替代或产品替代, 具有全社会范围内重塑工业体系的需求.

\section{3 储能、氢能产业需求及发展}

由于风电、太阳能发电的间歇、随机、波动特性 显著, 配备足够的储能容量和配套系统是其承担能源 供应主体责任的前提. 现有技术经济条件下, 综合分析 多种储能技术特点, 抽水蓄能、电化学储能、氢能对 于消纳大规模可再生能源具有较强的竞争力. 广义上 讲, 来源于风、光可再生能源的氢能也归属为储能, 但 由于氢可实现物质储存、能够转化为动力/电力、可以 作为治金还原剂等特点, 本文将单独讨论.

储能发展中, 第一个问题是我国需要配置多少储 能装机容量. 这需要考虑多种因素, 比如所采用储能技 术的特点、能源供应总体规划、能源消费总体规划等, 很难给出准确的回答.

如果对能源消费不作调整, 达到目前以化石能源 为主的能源供应水平, 至少需要配置1.4倍“风电+太阳 能发电”装机容量的抽水蓄能电站(抽水蓄能电站综合 效率按 $70 \%$ 计算). 在现有火电为主的电力供应体系中, 目前科学家开展的风光储容量匹配研究取“风电+太阳 能发电”装机容量的 10\% 3 0 \% 配置电化学储能系 统 ${ }^{[12,13]}$. 当“风电+太阳能发电”为主体时, 配置2倍电化 学储能电站(电化学效率按 $100 \%$, 储能时间按 $2 \mathrm{~h}$ 计算) 是必要的. 即使这样, 配备了上述储能容量的小规模电 网依然难以满足长时间阴雨天、长时间无风时用户侧 对电力的需求. 大电网可通过对不同地域的调控来消 除或缓解天气的影响, 但这种电力系统比现有系统要 更复杂得多, 对储能装机需求也更难以给出准确的
回答.

由于通过可再生能源制取的氢气能够实现跨季 节、跨年的存储, 配置1.4 2.0倍的氢能发电装机(氢燃 料电池发电效率按 $70 \%$ 计算, 氢燃气轮机联合循环按 $50 \%$ 计算)与波动性的可再生能源匹配, 较容易实现稳 定的电力输出, 从而达到目前的电力供应水平.

可见, 根据上述讨论及发电装机容量预测, 储能装 机规模将远超目前火电装机的2倍. 碳中和目标下, 可 再生发电装机比例逐步加大, 受限于技术和产能, 储能 装机也不可能完全跟随配套. 尽管火电机组容量比例 逐渐缩小, 但更重要的是, 火电将承担电力调峰作用, 满足电网平衡发电、供电的需求. 也可以说, 化石燃料 由数百万年前的太阳能转化而来, 是更广义的储能.

目前我国储能装机容量非常有限, 2019年, 储能装 机为 0.3 亿 $\mathrm{kW}$, 其中 $93.4 \%$ 为抽水蓄能, $5.3 \%$ 为电化学储 能(《储能产业研究白皮书2020》). 储能装机只有风 电、太阳能发电装机的 $7.3 \%$.

抽水蓄能技术成熟, 易实现, 优势明显. 我国规划 “十四五”末抽水蓄能装机规模达 0.6 亿 $\mathrm{kW}$, 是现有规模 的2倍. 但是，该技术更大规模的应用受到自然条件的 制约.

\subsection{1 电化学储能}

电化学储能具有能量密度大、功率密度高、循环 寿命长、快速充放电等优点. 近年来, 我国电化学储能 增长很快, 装机规模提升显著. 从2017年开始, 装机容 量年增长分别为 $45 \% 、 175 \% 、 59 \%$ 和 $91 \% .2020$ 年, 我 国电化学储能装机规模为 0.03 亿 $\mathrm{kW}$ (《储能产业研究 白皮书2021》).

锂离子电池技术成熟, 是目前主要的电化学储能 形式, 广泛应用于电动汽车中储电替代燃油车. 目前, 我国汽车保有量为 2.9 亿辆, 电动汽车保有量为 493 万 辆(公安部: https://app.mps.gov.cn/gdnps/pc/content.jsp? $\mathrm{id}=7993932$ ). 电动汽车替换传统燃油汽车是未来的发 展趋势 ${ }^{[14]}$, 既可解决汽车低碳清洁化的问题, 又可实现 能量的存储.

下面分析电动汽车对锂资源的需求. 全球锂资源 总量为 3190 5190万吨, 锂盐主要包含卤水锂和矿石锂 两种, 占比分别为 $62.6 \%$ 和 $37.4 \%{ }^{[15,16]}$. 我国锂资源为 541 万吨, 占全球锂总量的 $10.4 \%{ }^{[15]}$.

以特斯拉和比亚迪装配的三元锂电池为例, 能量 密度达到 $300 \mathrm{~W} \mathrm{~h} / \mathrm{kg}$, 每辆汽车装配的三元锂电池容量 为 $105 \mathrm{~kW} \mathrm{~h}$, 续航里程按 $500 \sim 600 \mathrm{~km}$. 以三元锂电池单 
位容量消耗锂 $0.53 \mathrm{~kg}$ 计算, 电动汽车消耗锂资源可由 式(2)计算:

$M_{\mathrm{Li}}=n_{\text {汽车 }} Q_{\text {电池 }} m_{\mathrm{Li}}$,

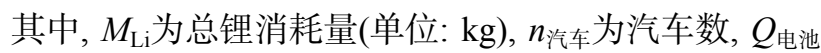
为平均每辆汽车的电池容量(单位: $\mathrm{kW} \mathrm{h}), m_{\mathrm{Li}}$ 为单位电 池容量消耗的锂质量(单位: $\mathrm{kg} /(\mathrm{kW} \mathrm{h})$ ).

根据Råde和Andersson ${ }^{[17]}$ 的研究, 主要应用的锂电 池三元锂(NCM811)、磷酸铁锂、锰酸锂单位电池单 位容量所需锂资源量(折合碳酸锂)分别为 $0.53 、 0.45$ 、

$0.43 \mathrm{~kg}$. 2.9 亿辆燃油汽车全部替换为电动汽车将需要 约1613万吨锂. 即使在现有消费水平下, 我国锂资源也 将严重紧缺. 在全球汽车保有量方面, 世界汽车组织 (Organisation Internationale des Constructeurs d'Automobiles, OICA)的最新数据(截至 2015 年)为 12.82 亿辆

(OICA: https://www.oica.net/category/vehicles-in-use/), 将其全部替换成电动汽车消耗的锂资源高达 7130 万吨, 远超世界现有锂资源总量. 如果考虑全世界人均汽车 保有量未来达到发达国家水平, 缺口更大.

另一方面，考虑燃油汽车全部替换为电动汽车的 储能能力, 电动汽车储能容量由式(3)计算:

$E_{\mathrm{Li}}=n_{\text {汽车 }} Q_{\text {电池 }}$,

其中, $E_{\mathrm{Li}}$ 为累计锂电池容量 (单位: $\left.\mathrm{kW} \mathrm{h}\right), n_{\text {汽车为汽车 }}$

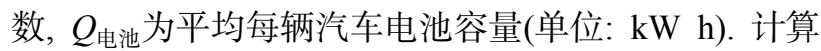
可得, 2.9 亿辆然油汽车全部替换为锂离子电动汽车的 储能容量为 305 亿 $\mathrm{kW} \mathrm{h}$, 满足新型电力系统对储能的 需求总量还有很大距离.

新型电力系统对储能的需求不像动力电池那样对 能量密度要求很高, 最重要的是要保证有足够的规模. 地壳中钠含量是锂含量的 1000 多倍, 且提取成本低、 制造价格低廉, 适合大规模储能应用. 钠离子电池储能 机理与锂离子电池类似，依靠钠离子在正负电极间的 往复移动实现充/放电工作, 表现出较高能量密度、较 长循环寿命长和成本较低的特点 ${ }^{[18,19]}$. 水系电池作为 新型二次离子电池, 电解液具有较高的离子电导率和 快速的反应动力学, 具有成本低、安全性好和功率密 度高等优点 ${ }^{[20 ~ 23]}$, 也具有广泛应用于大规模储能领域 的潜力. 超级电容器兼具物理电容器的大功率特性和 电池的高能量密度, 可作为电能存储器件, 对特定储能 应用场景很有吸引力 ${ }^{[24]}$. 考虑适应大规模储能需求, 钠 离子电池、水系电池、超级电容器等受资源约束较少
的电化学储能技术也具有很大的潜在发展空间.

\subsection{2 氢能}

氢能的大规模应用需要在氢制备、氢储运、氢利 用等环节建立起完整的体系. 电解水制氢技术成熟，具 有近100年的应用历史. 来源于风、太阳能的多余电力 可以及时地通过电解水制氢并储存. 电解水制氢技术 主要有碱水电解、质子交换膜水电解和固体氧化物水 电解. 目前碱水电解在工业中应用广泛，包括燃煤电厂 汽轮机氢冷常用该技术工艺. 质子交换膜水电解和质 子交换膜燃料电池是同一原理在氢制备和氢利用两个 过程的可逆应用, 制氢和发电效率高, 都需要用铂作为 催化剂. 固体氧化物水电解不需要贵金属催化剂, 但要 在600 $1000^{\circ} \mathrm{C}$ 高温下运行, 相对不成熟, 尤其要注意安 全性. 氢进一步可以通过燃料电池、内燃机或燃气轮 机输出动力、电力或热能, 也可以作为工业中的还原 剂. 总体上，氢能利用的产业链条完整，没有明显的技 术瓶颈.

铂是质子交换膜水电解和质子交换膜燃料电池中 至关重要的催化剂, 在现有技术体系下不可或缺. 截至 2018 年, 全球铂储量约为 $32430 \mathrm{t}$, 主要分布在南非 (90.90\%)、俄罗斯 $(5.63 \%) 、$ 津巴布韦 $(1.73 \%) 、$ 美国 $(1.30 \%)$ 和加拿大 $(0.45 \%)^{[25]}$. 目前我国的氢燃料电池已 开始量产, 主要用于交通, 单位功率载铂量为 0.3 0.4 g/kW，高于本田Clarity燃料电池 $(0.12 \mathrm{~g} / \mathrm{kW})$ 和 丰田MIRAI燃料电池 $(0.175 \mathrm{~g} / \mathrm{kW})^{[25]}$, 未来需进一步提 升载铂技术以降低单位功率负载量.

目前国内燃料电池车开发以质子交换膜燃料电池 为主，借鉴代表性氢燃料电池汽车车型的功率参数(奔 驰GLC F-Cell: $100 \mathrm{~kW}$; 丰田MIRAI: 114/90 kW; 本田 Clarity: $103 \mathrm{~kW}$; 现代NEXO: $113 / 95 \mathrm{~kW})^{[26]}$, 取单辆汽 车功率为 $100 \mathrm{~kW}$ 进行研究, 载铂量按 $0.15 \mathrm{~g} / \mathrm{kW}$ 计算, 得出现有 493 万辆电动汽车替换为氢燃料电池汽车时 我国铂金属需求量约为 $74.0 \mathrm{t}$, 恰好与我国2018年铂实 际消耗量 $74.6 \mathrm{t}$ 相当. 如果将我国 2.9 亿辆汽车全部替换 为氢燃料电池汽车, 我国的铂需求量将高达 $4350 \mathrm{t}$, 占 世界铂资源总量的 $13.41 \%$. 全球 12.82 亿辆汽车(数据来 源: OICA，2015年汽车保有量)全部替换成氢燃料电池 汽车将消耗的铂资源高达 $19230 \mathrm{t}$ ，达到世界现有铂资 源总量的 $59.30 \%$. 铂资源将是一个重要的限制性因素.

另一方面，需要探讨燃油汽车替换为氢燃料电池汽 车后的储能能力. 奔驰GLC F-Cell储氢量为 $4.4 \mathrm{~kg}$, 丰田 MIRAI储氢量为 $5.0 \mathrm{~kg}$, 本田Clarity储氢量为 $5.5 \mathrm{~kg}$, 现代 
$\mathrm{NEXO}$ 储氢量为 $6.3 \mathrm{~kg}^{[26]}$, 平均单辆汽车储氢量为 $5.3 \mathrm{~kg}$, 续航里程为 $500 \sim 600 \mathrm{~km}$, 氢气热值为 $1.4 \times 10^{8} \mathrm{~J} / \mathrm{kg}$. 按照式 (4)计算氢燃料电池汽车能够储存的电力:

$E_{\text {氢储 }}=\frac{n_{\text {汽车 }} m_{\text {单 }} q_{\text {氢气 }}}{3600 \eta}$,

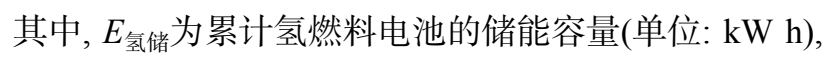

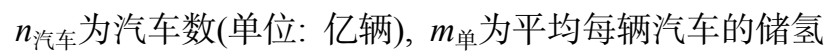

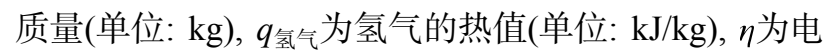
解水制氢效率(取 $80 \%$ ). 计算可得, 2.9 亿辆燃油汽车全 部替换为氢燃料电池汽车的储能容量为 748 亿 $\mathrm{kW} \mathrm{h}$.

氢气火焰传播速度快、爆炸极限范围宽. 出于安 全考虑，民用燃烧供热等不是理想的选项.工业应用 中，主要成分是氢气的合成气燃气轮机有现成的技术 及应用, 发电侧电解水制氢-储氢-燃机发电调峰技术路 线能够避免低质量密度氢的输运, 氢气用于燃气轮机 发电相对成熟, 对今后能源体系的构建具有重要作用. 另一方面, 对现有工艺流程进行改进后, 氢作为冶炼工 业的还原剂实现起来也相对容易.

\section{4 结论及展望}

基于我国目前的能源、电力生产及消费结构分析, 本文对实现碳中和目标下能源结构的调整瓶颈和解决 途径进行了讨论, 主要结论及展望如下.
（1）2060年实现碳中和时，在我国能源消费总量没 有大变化的前提下, 化石燃料比例为 $20 \%$ 左右, 可再生 能源比例为 $70 \%$ 左右.

（2）实现碳中和需要有比目前电力总装机更大规 模的装机容量, 风电、太阳能发电装机将至少为目前 火电装机的 2 倍. 需要改变现有能源生产和能源消费模 式以适应今后能源结构的调整.

（3）配置适当的储能装机容量是风电、太阳能发 电承担主体发电责任的保证. 现有技术水平下, 抽水蓄 能、电化学储能、氢能具有竞争力. 不同于动力储能 对电池高密度的追求, 新能源消纳最重要的是有足够 的规模. 抽水蓄能受限于地理环境, 规模不足以支撑风 光发电对储能发展的需求. 锂离子电池受限于锂资源, 氢能燃料电池受限于铂资源, 完全依赖锂离子电池、 氢燃料电池, 即使能够解决交通问题, 也会面临资源瓶 颈. 未来的交通体系需要在现有基础上重新规划, 比如 加大轨道交通的范围、改变交通习惯等.

（4）大规模消纳可再生能源需要考虑多种储能技 术储备, 多元发展. 氢燃气轮机、氢冶炼等相对成熟的 路线技术具有支撑今后大规模可再生能源消纳的潜在 优势. 分布式储热、压缩空气储能、非贵金属催化的 氢燃料电池、钠/铅酸电池、水系电池、超级电容器及 其他多种具有技术经济性、可实现大规模应用的储能 技术也都具有良好的发展空间.

\section{参考文献}

1 National Bureau of Statistics of China. 2020 China Statistical Yearbook (in Chinese). Beijing: China Statistics Press, 2020 [国家统计局. 2020 中国 统计年鉴. 北京: 中国统计出版社, 2020]

2 European Commission. EU Energy in Figures 2020. Luxembourg: Publications Office of the European Union, 2020

3 British Petroleum. Statistical Review of World Energy. 2021

4 Yi Y C. China offshore wind power (in Chinese). Electr Power Equip Manage, 2018, 12: 81-83 [易跃春. 中国海上风电. 电力设备管理, 2018, 12: 81-83]

5 Li K, He F N. Analysis on mainland China's solar energy distribution and potential to utilize solar energy as an alternative energy source (in Chinese). Prog Geogr, 2010, 29: 1049-1054 [李柯, 何凡能. 中国陆地太阳能资源开发潜力区域分析. 地理科学进展, 2010, 29: 1049-1054]

6 Huang Q L. Energy structure adjustment and renewable energy development (in Chinese). Modern Electr Power, 2007, 24: 1-5 [黄其励. 加快能源 结构调整, 积极发展可再生能源. 现代电力, 2007, 24: 1-5]

7 Huang Q H. Major challenges and strategic choices in deepening China's industrialization process during the "Fourteenth Five-Year" period (in Chinese). J CCPS (CAG), 2020, 24: 5-16 [黄群慧. “十四五”时期深化中国工业化进程的重大挑战与战略选择. 中共中央党校(国家行政学院) 学报, 2020, 24: 5-16]

8 International Energy Agency. World Energy Outlook 2019. 2019

9 British Petroleum. British Petroleum Energy Outlook 2020 Edition. 2020

10 CNPC Economics and Technology Research Institute. World and China Energy Outlook 2019 (in Chinese). 2019 [中国石油经济技术研究院. 世 界与中国能源展望2019. 2019]

11 British Petroleum. Statistical Review of World Energy (2020 Edition). 2020 
12 Zhang H N, Tao Y B, Mei H, et al. Collaborative optimal scheduling model of photovoltaic-wind-battery cluster based on cooperative game (in Chinese). Therm Power Gen, 2021, 50: 1-9 [张海宁, 陶以彬, 梅慧, 等. 基于合作博亦的风光储集群协同优化调度模型. 热力发电, 2021, 50: 19]

13 Li P, Fang B M, Qi T Y, et al. Method on capacity proportion optimization of wind, solar power and battery energy storage system for regional power grid based on source-load matching (in Chinese). Electr Power, 2021, https://kns.cnki.net/kcms/detail/11.3265.tm.20210430.1417.002.html [李湃, 方保民, 祁太元, 等. 基于源-荷匹配的区域电网风光储容量配比优化方法. 中国电力, 2021, https://kns.cnki.net/kcms/detail/11.3265. tm.20210430.1417.002.html]

14 Ouyang M G. Meet the new era of new energy intelligent electric vehicles (in Chinese). Sci Technol Rev, 2019, 37 : 1 [欧阳明高. 迎接新能源智能 化电动汽车新时代. 科技导报, 2019, 37: 1]

15 Su T, Guo M, Liu Z, et al. Comprehensive review of global lithium resources (in Chinese). J Salt Lake Res, 2017, 27: 104-111 [苏粀, 郭敏, 刘忠, 等. 全球锂资源综合评述. 盐湖研究, 2017, 27: 104-111]

16 Kesler S E, Gruber P W, Medina P A, et al. Global lithium resources: Relative importance of pegmatite, brine and other deposits. Ore Geol Rev, 2012, 48: 55-69

17 Råde I, Andersson B A. Requirement for metals of electric vehicle batteries. J Power Sources, 2001, 93: 55-71

18 Xie J S, Xiao Z M, Zuo W H, et al. Research progresses of sodium cobalt oxide as cathode in sodium ion batteries (in Chinese). Acta Chim Sin, 2021, 79: 1232-1243 [谢佶晟, 肖竹梅, 左文华, 等. 钠离子电池钴酸钠正极材料研究进展. 化学学报, 2021, 79: 1232-1243]

19 Ma H, Zhang H R, Xue M Q. Research progress and practical challenges of aqueous sodium-ion batteries (in Chinese). Acta Chim Sin, 2021, 79: 388-405 [马慧, 张桓荣, 薛面起. 水系钠离子电池的研究进展及实用化挑战. 化学学报, 2021, 79: 388-405]

20 Dai Y H, Gan Z W, Ruan Y S, et al. Research progress of aqueous zinc ion batteries and their key materials (in Chinese). J Chin Ceram Soc, 2021, 49: 1323-1336 [戴宇航, 甘志伟, 阮雨杉, 等. 水系锌离子电池及关键材料研究进展. 硅酸盐学报, 2021, 49: 1323-1336]

$21 \mathrm{Hu} \mathrm{L}, \mathrm{Wu} \mathrm{Z}, \mathrm{Lu} \mathrm{C}$, et al. Principles of interlayer-spacing regulation of layered vanadium phosphates for superior zinc-ion batteries. Energy Environ Sci, 2021, 14: 4095-4106

$22 \mathrm{Ma} \mathrm{L}$, Chen $\mathrm{S}$, Li H, et al. Initiating a mild aqueous electrolyte $\mathrm{Co}_{3} \mathrm{O}_{4} / \mathrm{Zn}$ battery with $2.2 \mathrm{~V}$-high voltage and 5000-cycle lifespan by a Co(III) richelectrode. Energy Environ Sci, 2018, 11: 2521-2530

23 Jiang L, Wu Z, Wang Y, et al. Ultrafast zinc-ion diffusion ability observed in 6.0-nanometer spinel nanodots. ACS Nano, 2019, 13: 10376-10385

24 Dong D, Zhang Y, Xiao Y, et al. Mechanochemistry coupled with $\mathrm{MgCO}_{3}$ one-step activation to prepare coal-based hierarchical porous carbon for supercapacitors. J Power Sources, 2021, 503: 230049

25 Ma T, Zhang W Y, Jia D L. The present situation of platinum metal resources and demand trend (in Chinese). Conserv Util Mineral Resour, 2019, 5: 90-97 [马腾, 张万益, 贾德龙. 铂资源现状与需求趋势. 矿产保护与利用, 2019, 5: 90-97]

26 Xia Y Z, Hu Y W, Wang J D, et al. Security system analysis of fuel cell vehicles (in Chinese). Chin Battery Ind, 2021, 25: 26-37 [夏玉珍, 胡神玮, 王杰董, 等. 燃料电池汽车安全系统分析. 电池工业, 2021, 25: 26-37] 
Summary for “我国能源生产、消费、储能现状及碳中和条件下变化趋势”

\title{
Current status and trends in energy production, consumption, and storage under carbon neutrality conditions in China
}

\author{
Yongsheng Zhang*, Duo Dong, Yi Xiao, Tao Wang \& Jiawei Wang \\ Key Laboratory of Power Station Energy Transfer Conversion and System, Ministry of Education, School of Energy Power and Mechanical \\ Engineering, North China Electric Power University, Beijing 102206, China \\ * Corresponding author, E-mail: yszhang@ncepu.edu.cn
}

Carbon peak and carbon neutrality are major demands and challenges in China's energy development. This study analyzes the characteristics of China's existing energy production structure, installed electric capacity, energy consumption, and electric consumption in different sectors based on statistical data to achieve carbon neutrality. Further, the energy structure for achieving carbon neutrality, as well as the problems and bottlenecks faced by China's future electric system structure adjustment, is discussed.

Energy production and consumption have been increasing since the 1990s, due to China's fast economic expansion, with coal dominating production and consumption. Renewable energy accounts for a modest percentage of overall energy production, but its installed capacity is rapidly growing. Particularly, the installed capacity of wind and photovoltaic power are both at the highest global level; however, their proportion in the overall power generation is still low. Industrial energy consumption accounts for the largest percentage of total energy consumption, accounting for $65 \%-75 \%$. Significantly, current industrial electricity consumption is consistent with the quantity of thermal power produced. Industrial production process technology can be optimized for energy consumption since peak and frequency modulation of thermal power generation is relatively convenient. Optimizing energy production and satisfying industrial energy consumption will be beneficial in the future adjustment of China's power structure.

The total energy consumption in China may not significantly change when carbon neutrality is achieved in 2060 . The proportion of fossil fuels will be about $20 \%$, whereas renewable energy about $70 \%$. In addition, the installed capacity of wind and solar will be about twice the current existing fossil fuel-fired electricity to achieve carbon neutrality. Thus, adjusting the existing energy production and consumption model and configuring an appropriate energy storage capacity are crucial.

An appropriate configuration of energy storage installed capacity ensures that wind and solar power can handle most of the power generation load. Pumped-storage energy, electrochemical energy storage, and hydrogen energy have shown significant advantages at the current level of technology. Unlike the quest for high-density batteries for power energy storage, adequate scaleup is critical for new energy consumption. However, the geographical environment, lithium and platinum resources limit the application of pumped-storage energy, lithium-ion batteries, and hydrogen fuel batteries, respectively. Resource constraints hinder the use of lithium-ion batteries and hydrogen fuel cells to solve traffic problems. Therefore, the future transportation system must be re-planned based on current conditions, such as increasing rail-road transport ratio and changing traffic habits.

Large-scale use of renewable energy requires consideration of multiple energy storage technology reserves and diverse development. Relatively developed route technologies, such as hydrogen gas turbines and smelting, have the potential advantages to support large-scale renewable energy consumption in the future. Many energy storage technologies with technical economy and large-scale applications also have potentials for further development, like distributed heat storage, compressed air energy storage, nonprecious metal-catalyzed hydrogen fuel cells, sodium/lead-acid batteries, liquid flow batteries, supercapacitors, etc.

carbon neutrality, energy production and consumption, wind power, solar power, energy storage, hydrogen energy doi: 10.1360/TB-2021-0797 